Institute of $\mathbf{F}_{\text {ood and }} \mathbf{A g r i c u l t u r a l}_{\text {griences }}$

\title{
Como Realizar un Plan de Gastos - Cuarto Paso: ¿Cuánto Gasta Usted? ${ }^{1}$
}

Nayda I Torres ${ }^{2}$

Use sus archivos para averiguar cuánto dinero gasta todos los meses. Existen dos tipos de gastos que usted necesita controlar.

Los Gastos Fijos normalmente son aquellos que usted paga de manera regular. Aquí les mostramos algunos gastos fijos comunes:

- Cuidado de los hijos

- Alquiler o hipoteca

- Gastos comunes de la casa (el agua, la electricidad, el teléfono o el combustible)

- Pagos aplazados (automóvil o préstamos)

- Pólizas de seguros

- Depósitos de ahorro

La mayoría de los gastos fijos se pagan todos los meses, pero otros tienen que ser pagados cada tres o seis meses o una vez al año. Usted normalmente puede planificar estos pagos y ahorrar una porción del total para pagar estas facturas antes de vencer.
Los Gastos Flexibles son aquellos que no ocurren de manera regular. Aquí les mostramos algunos gastos que se consideran flexibles:

- $\quad$ Comida, papel y productos limpieza

- Ropa y artículos personales (limpieza, cortes de pelo, accesorios, etc.)

- Transporte (gasolina, reparación del automóvil, transporte público, etc.)

- Cuidados médicos (facturas del doctor, medicinas, etc.)

- Educación y recreo (libros, revistas, películas, teatro, vacaciones, etc.)

- Regalos y donaciones (cumpleaños, fiestas, caridad, etc.)

La lista de gastos flexibles puede variar de mes a mes. Las personas que mantienen un diario de gastos por primera vez se sorprenden al ver cuanto gastan en cosas que realmente no necesitan o quieren. Si usted tiene un mejor control sobre sus gastos flexibles, tendrá más

1. Este documento es la Hojuela FCS7170-Span, una serie del Departamento de Ciencias de la Familia, Juventud y Comunidad, Servicio de Extensión Cooperativa de Florida, Instituto de Alimentos y Ciencias Agrícolas, Universidad de Florida. Fecha de publicación: Octubre 2002. Por favor visite el web de EDIS http://edis.ifas.ufl.edu

2. Escrito por Nayda I. Torres, Profesora, Familia y Economía del Consumidor y la versión en Inglés ha sido revisada por Josephine Turner, CFP, Profesora, Familia y Economía del Consumidor, Servicio de Extensión Cooperativa, Departamento de Ciencias de la Familia, Juventud y Comunidad, Instituto de Alimentos y Ciencias Agrícolas, University of Florida, Gainesville, 32611. Traducido por: Sergio Romero.

El Instituto de Alimentos y Ciencias Agrícolas es un patrono que ofrece igualdad de oportunidad de empleo, autorizado a proveer investigación, información educativa y otros servicios a individuos y a instituciones que ejerzan sus funciones sin tomar en consideración raza, color, sexo, edad, incapacidad o nacionalidad. Para información sobre como obtener otras publicaciones del Servicio de Extensión, comuníquese con la Oficina del Servicio de Extensión Cooperativa de su Condado. Servicio de Extensión Cooperativa de Florida / Instituto de Alimentos y Ciencias Agrícolas / Universidad de Florida, Christine Taylor Waddill, Decano 
facilidad de cubrir sus gastos fijos, evitar pagos extra por no pagar a tiempo y conseguir sus objetivos.

Use las tablas 1 y 2 para calcular sus gastos fijos y flexibles. Algunas personas piensan que es mejor averiguar cuánto gastan todos los meses. Otros calculan sus gastos durante cada semana. Puesto que algunos gastos normalmente se hacen semanalmente o mensualmente, puede ser útil calcular sus gastos de ambas maneras. Esto le ayudará a ver más claramente cómo usted gasta su dinero.

En la tabla 3, sume los gastos fijos y los gastos flexibles para ver cuanto gasta todos los meses.

Recuerde que estas tablas son para ayudarle a hacer su primer plan de gastos. Experimente para ver que sistema se adapta mejor a sus necesidades. 
Tabla 1.

GASTOS FIJOS

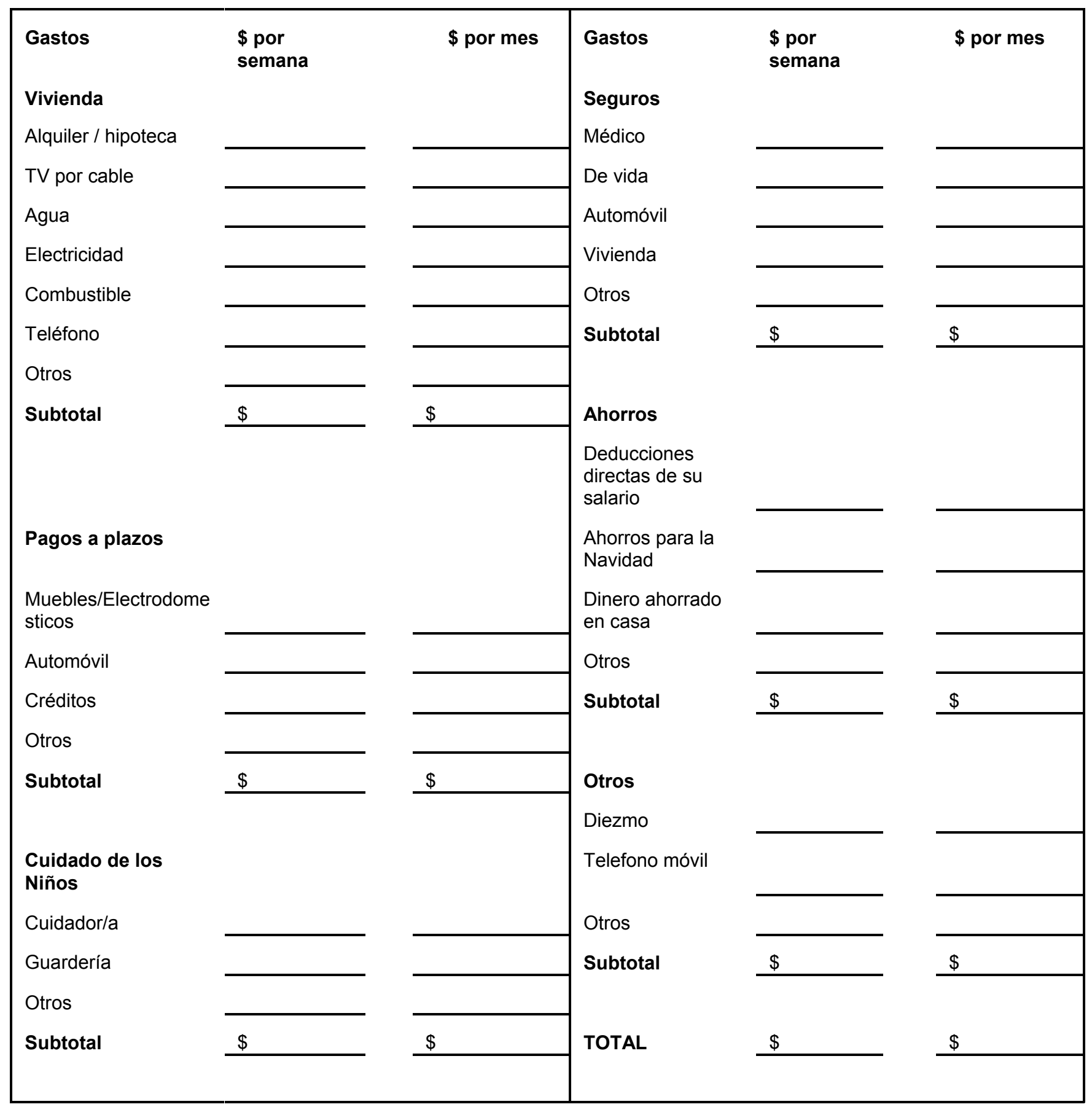


Tabla 2.

GASTOS FLEXIBLES

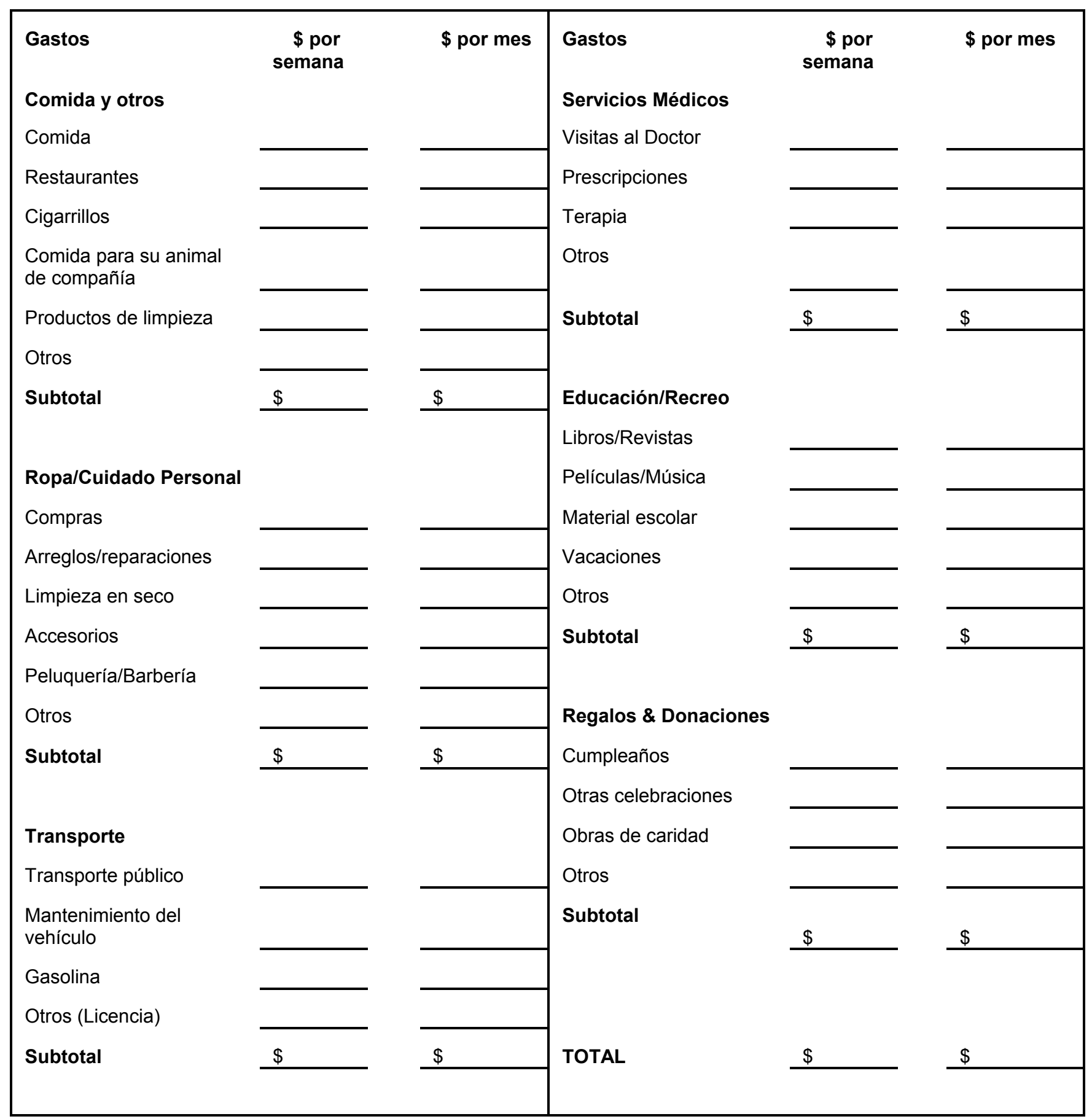


En la tabla 3, sume los gastos fijos y los gastos flexibles para ver cuanto gasta todos los meses..

Table 3.

Gastos

\section{Gastos Fijos}

Vivienda

Pagos a plazos

Cuidado de los niños

Seguros

Ahorros

Otros

Total

\section{Gastos Flexibles}

Comida y otros

Ropa y cuidado personal

Transporte

Servicios Médicos

Educación/Recreo

Regalos y Donaciones

Otros

Total

Gran Total
\$ Por Mes
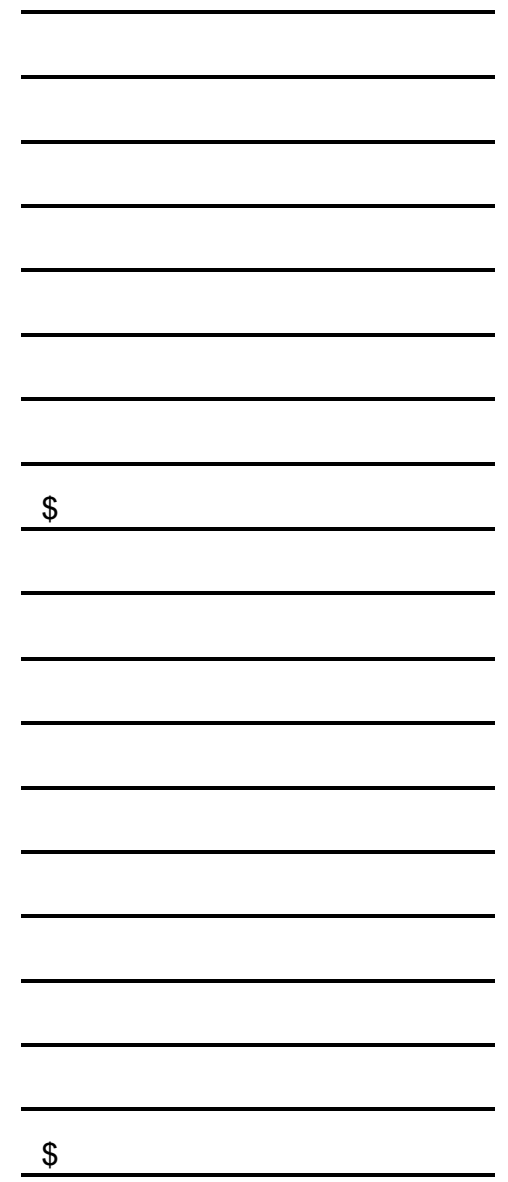

$\$$

Recuerde que estas tablas son para ayudarle a hacer su primer plan de gastos. Experimente para ver que sistema se adapta mejor a sus necesidades. 